\title{
Functional and radiological outcome of anterior retroperitoneal versus posterior transforaminal interbody fusion in the management of single-level lumbar degenerative disease
}

\author{
Roberto Bassani, MD, ${ }^{1}$ Carlotta Morselli, MD, ${ }^{1,2}$ Amos M. Querenghi, MD, ${ }^{1}$ Alessandro Nuara, MD, ${ }^{3}$ \\ Luca Maria Sconfienza, MD, 1,4 and Giuseppe M. Peretti, MD 1,4
}

${ }^{1}$ IRCCS Istituto Ortopedico Galeazzi, Milan; ${ }^{2}$ Department of Human Neuroscience, "Sapienza" University, Rome; and ${ }^{3}$ Residency Program in Orthopedics and Traumatology, and 4Department of Biomedical Sciences for Health, University of Milan, Italy

\begin{abstract}
OBJECTIVE In this study the authors compared the anterior lumbar interbody fusion (ALIF) and posterior transforaminal lumbar interbody fusion (TLIF) techniques in a homogeneous group of patients affected by single-level L5-S1 degenerative disc disease (DDD) and postdiscectomy syndrome (PDS). The purpose of the study was to analyze perioperative, functional, and radiological data between the two techniques.
\end{abstract}

METHODS A retrospective analysis of patient data was performed between 2015 and 2018. Patients were clustered into two homogeneous groups (group 1 = ALIF, group 2 = TLIF) according to surgical procedure. A statistical analysis of clinical perioperative and radiological findings was performed to compare the two groups. A senior musculoskeletal radiologist retrospectively revised all radiological images.

RESULTS Seventy-two patients were comparable in terms of demographic features and surgical diagnosis and included in the study, involving $32(44.4 \%)$ male and 40 (55.6\%) female patients with an average age of 47.7 years. The mean follow-up duration was 49.7 months. Thirty-six patients (50\%) were clustered in group 1, including 31 (86\%) with DDD and $5(14 \%)$ with PDS. Thirty-six patients (50\%) were clustered in group 2, including $28(78 \%)$ with DDD and $8(22 \%)$ with PDS. A significant reduction in surgical time (107.4 vs 181.1 minutes) and blood loss (188.9 vs $387.1 \mathrm{ml}$ ) in group 1 ( $p<$ $0.0001)$ was observed. No significant differences in complications and reoperation rates between the two groups $(p=$ 0.561 ) was observed. A significant improvement in functional outcome was observed in both groups ( $p<0.001)$, but no significant difference between the two groups was found at the last follow-up. In group 1, a faster median time of return to work (2.4 vs 3.2 months) was recorded. A significant improvement in L5-S1 postoperative lordosis restoration was registered in the ALIF group (9.0 vs 5.0, $p=0.023$ ).

CONCLUSIONS According to these results, interbody fusion is effective in the surgical management of discogenic pain. Even if clinical benefits were achieved earlier in the ALIF group (better scores and faster return to work), both procedures improved functional outcomes at last follow-up. The ALIF group showed significant reduction of blood loss, shorter surgical time, and better segmental lordosis restoration when compared to the TLIF group. No significant differences in postoperative complications were observed between the groups. Based on these results, the ALIF technique enhances radiological outcome improvement in spinopelvic parameters when compared to TLIF in the management of adult patients with L5-S1 DDD. https://thejns.org/doi/abs/10.3171/2020.6.FOCUS20374

KEYWORDS anterior lumbar interbody fusion; transforaminal lumbar interbody fusion; degenerative disc disease; radiological outcome; functional outcome; lumbar lordosis

I $\mathrm{N}$ adult patients affected by degenerative disc disease (DDD) with chronic low-back pain, interbody fusion is performed to achieve pain relief with the aim of first obtaining a solid bone fusion, and second the restoration of the segmental lordosis, according to the pelvic incidence (PI). Different techniques-posterior, anterior, lateral, and combined-have been developed and advantages and drawbacks have been widely investigated. ${ }^{1-8}$ The advantages of the anterior lumbar interbody fusion (ALIF) technique are the possibility to achieve a com-

ABBREVIATIONS ADD = adjacent disc disease; $A L I F=$ anterior lumbar interbody fusion; $A L L=$ anterior longitudinal ligament; $D D D=$ degenerative disc disease; IQR = interquartile range; $\mathrm{LL}=$ lumbar lordosis; $\mathrm{LLL}=$ lower $\mathrm{LL} ; \mathrm{ODI}=$ Oswestry Disability Index; $\mathrm{PDS}=$ postdiscectomy syndrome; $\mathrm{PI}=$ pelvic incidence; $\mathrm{PT}$ = pelvic tilt; $\mathrm{SS}$ = sacral slope; TLIF = transforaminal lumbar interbody fusion; VAS = visual analog scale.

SUBMITTED May 1, 2020. ACCEPTED June 9, 2020.

INCLUDE WHEN CITING DOI: 10.3171/2020.6.FOCUS20374. 
plete anterior discectomy, under direct vision, after resection of the anterior longitudinal ligament (ALL) and the insertion of large and lordotic cages. This approach, using modern minimally invasive techniques, allows for an optimal local lordosis restoration and an indirect foraminal decompression with early perioperative pain reduction, preserving the integrity of the posterior tension band. ${ }^{9}$ ALIF approach-related complication rates range between $8.4 \%$ and $31.1 \%$ in large patient series. ${ }^{2,3}$ The most important complications are vascular injuries, especially venous, accounting for between $1.9 \%$ and $24 \%$, mostly at the L4-5 space (iliolumbar vein). ${ }^{4,5}$ Visceral injuries are uncommon. Neural structure injuries can include sympathetic dysfunction, and retrograde ejaculation in males (3\%-5\% of male cases). ${ }^{5,6}$ Among posterior approaches, the advantages of transforaminal lumbar interbody fusion (TLIF) include unilateral access to the disc and eventual direct monolateral decompression reducing perineural scarring tissue, and the possibility to perform both interbody and posterolateral fusion. TLIF approach-related complications are dural tears and root injury, poor discectomy and endplate preparation, and screw and cage malpositioning or migration. ${ }^{7,8}$ According to the literature, the perioperative TLIF complication rate accounts for between $14.2 \%$ and $25.4 \%$ in large series. ${ }^{7,8}$ Rate of dural tears range between $0 \%$ and $20 \%$, root injuries occur in $1 \%-3 \%$ of cases, symptomatic screw misplacement occurs in 4\%-9\% of cases, and cage migration is an uncommon but potentially serious complication. ${ }^{8}$ Many comparative studies report the same fusion rate between these different techniques and better radiological results in terms of segmental lordosis for ALIF. ${ }^{10}$ However, comparative data on surgical results and functional outcome of each procedure are unconvincing, probably because heterogeneous samples are analyzed, resulting in limited statistical power. ${ }^{2,10}$ The purpose of this study was to compare retrospectively the two techniques (ALIF vs TLIF) in two homogeneous groups of patients in terms of sample size, sex, and age affected by single-level L5-S1 DDD and postdiscectomy syndrome (PDS). An analysis of perioperative, functional, and radiological data between the two techniques was performed.

\section{Methods}

This is a retrospective analysis from the review of the Spine Surgery 2 Unit of the IRCCS Galeazzi Hospital database between 2015 and 2018, with a minimum 2-year follow-up (mean 49.7 months). Clinical and radiological deidentified registries were used to track patient care and outcome without direct patient involvement, even if informed consent was obtained. Patients $\geq 18$ years old, with single-level L5-S1 interbody fusion performed by ALIF and TLIF techniques for DDD or PDS, were selected and included. The TLIF technique was performed in cases of DDD or PDS associated with bone stenosis. In pure DDD or PDS with or without association of soft stenosis, the ALIF procedure was performed (indirect decompression). Only patients with complete information in the database at the last follow-up were considered for the study. Patients with significant comorbidities (diabetes, inflammatory diseases, BMI $\geq 30 \mathrm{~kg} / \mathrm{m}^{2}$ ), posttraumatic deformity, infections, spondylolisthesis, or previous fusion, were excluded. Surgery was performed to achieve pain improvement and to prevent neurological worsening. A single senior spinal surgeon trained in anterior approaches (R.B.) treated all included patients clustered into the anterior (group 1) and posterior (group 2) groups. Clinical, radiological, and surgical data of each patient were collected until final followup. Clinical and functional outcomes were assessed by visual analog scale (VAS) scores for back pain and leg pain and the Oswestry Disability Index (ODI) scoring systems. A spine registry (the IOG Spine-Reg) was used to track clinical follow-up. Radiological follow-up was obtained on the second postoperative day, after 3 months, and then every 12 months for 2 years. All radiological data were obtained by direct measurement of biplanar full-spine radiographs on EOS imaging platforms and collected in the institutional radiological registry. Each image was imported into Sectra Workstation IDS7 and the spinopelvic parameters were calculated using Ortho Toolbox (Fig. 1). Lateral and coronal images were reviewed, and pre- and postoperative spinopelvic parameters were assessed and compared. Fusion at the last follow-up was retrospectively assessed by a musculoskeletal radiologist with 15 years of experience in musculoskeletal imaging (L.M.S.) on both CT scans and radiographs, which, could be less subject to artifacts, particularly in the presence of tantalum cages. The Brantigan interbody fusion grading system was used to define radiological evidence of fusion on $\mathrm{CT},{ }^{11}$ and grades 4 and 5 were considered as fusion. The presence of bone bridging in the disc space or in the anterior part of the disc space on radiographs was also used to confirm fusion.

\section{Statistical Analysis}

Statistical analyses were performed using GraphPad Prism (version 5.0, GraphPad Software Inc.). Data were expressed as median and interquartile range (IQR) or mean and standard deviation (SD) as specified in each case. Normal distribution of all variables was tested using the Shapiro-Wilk test. One-way ANOVA and the KruskalWallis test with Dunn's posttest were applied to assess differences among different groups and time points in cases of normal and nonnormal data distribution, respectively. Similarly, the Student t-test or Mann-Whitney test were used for the comparisons between the two groups. A p value $<0.05$ was considered statistically significant.

\section{Results \\ Population}

The analysis of our database showed 153 patients who underwent surgery for single-level L5-S1 degenerative disease treated with ALIF and TLIF techniques. Of these 153 patients, $56(36.6 \%)$ were excluded due to exclusion criteria and $25(16.3 \%)$ were excluded for incomplete data at the last follow-up. All of the 72 included patients were comparable in terms of demographic features and diagnoses (Table 1). Thirty-two patients were male and 40 female, the average age was $47.7 \pm 11.5$ years (range $28-83$ years), and the median age was 46 years. The mean 

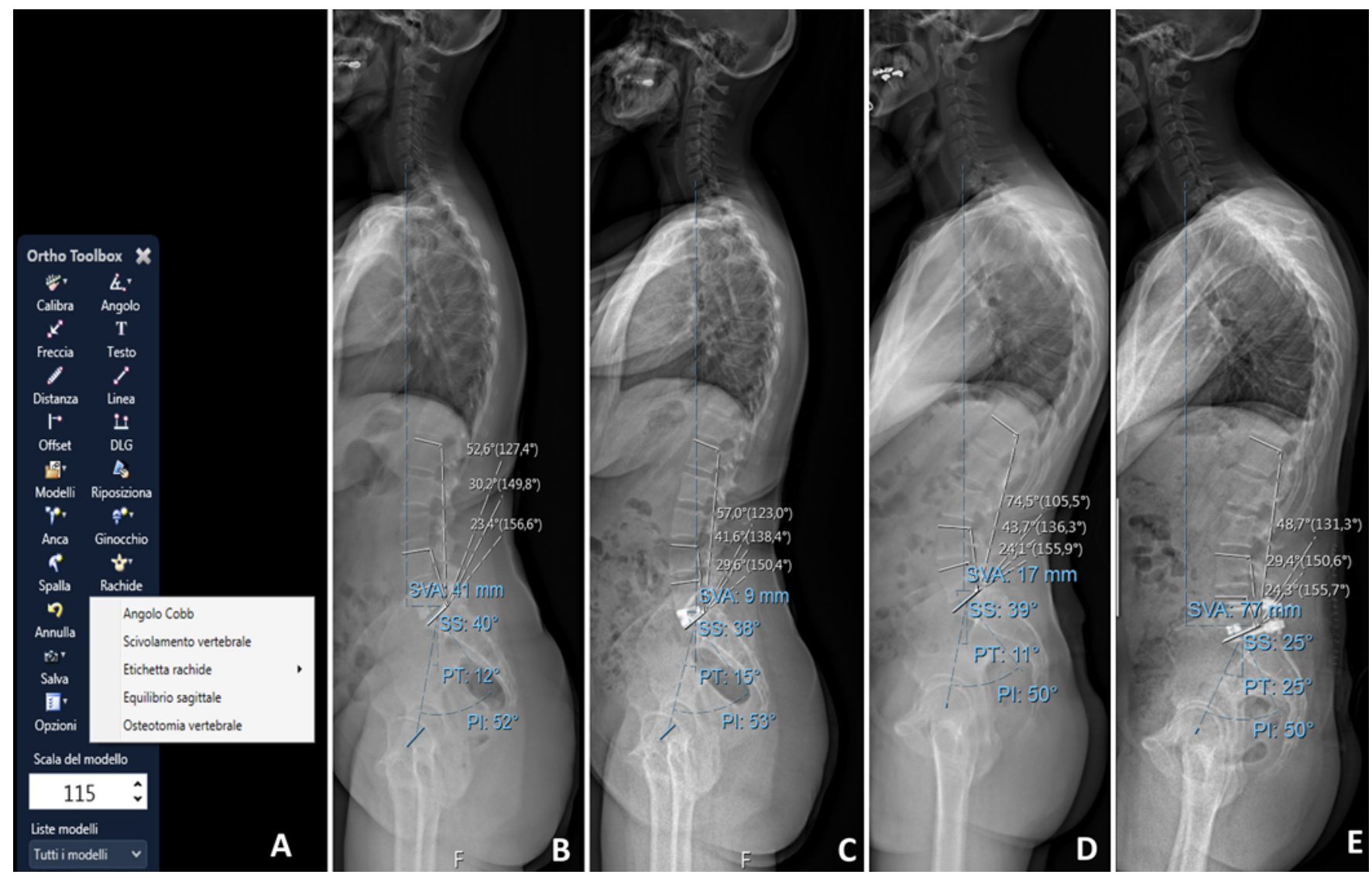

FIG. 1. Pre- and postoperative radiological measurement (A) of full-spine radiographs in the ALIF (B and C) and TLIF (D and E) groups. $\mathrm{PI}$ is measured by drawing an angle between a line perpendicular to the sacral plate at its midpoint and a line connecting the same point to the center of the bicoxofemoral axis. PT is measured by an angle between the center of the superior S1 endplate and a vertical line. SS is measured by an angle between the center of the superior endplate of $S 1$ and the horizontal plane. LL is measured as the angle between the upper endplate of $L 1$ and superior endplate of the sacrum, between the upper endplate of $L 4$ and superior endplate of the sacrum, and between the upper endplate of L5 and superior endplate of the sacrum (L1-S1, L4-S1, and L5-S1).

follow-up duration was $49.7 \pm 27.6$ months (range 12-108 months). Thirty-six patients $(50 \%)$ were clustered in group 1 (12 men, 24 women, average age $46.09 \pm 9.15$ years). Thirty-six patients $(50 \%)$ were clustered in group 2 (20 men, 16 women, mean age $50.55 \pm 13.41$ years). There were 31 patients with DDD in group $1(86 \%)$ and 28 patients with DDD in group 2 (78\%). Five patients (14\%) had PDS in group 1 and 8 (22\%) had PDS in group 2.

\section{Spinopelvic Parameters}

In group 1 , the mean preoperative PI was $49.4^{\circ} \pm 11^{\circ}$ (median $46^{\circ}$ ), the mean pelvic tilt (PT) was $16.8^{\circ} \pm 7.3^{\circ}$ (median $17^{\circ}$ ), and mean sacral slope (SS) was $31.1^{\circ} \pm 8.3^{\circ}$ (median $33^{\circ}$; Table 2). The mean lumbar lordosis (LL) at L1-S1 was $48.7^{\circ} \pm 7.3^{\circ}$ (median $49^{\circ}$ ). Lower LL (LLL) at L4-S1 was $31.5^{\circ} \pm 7.5^{\circ}$ (median $31.7^{\circ}$ ) and L5-S1 LL was $17^{\circ} \pm 6.2^{\circ}\left(\right.$ median $\left.16.5^{\circ}\right)$.

In group 2 , the mean preoperative PI was $50.9^{\circ} \pm 9.7^{\circ}$ (median $49^{\circ}$ ), the mean PT was $17.2^{\circ} \pm 10^{\circ}\left(\right.$ median $\left.16^{\circ}\right)$, and mean SS was $33.5^{\circ} \pm 6^{\circ}\left(\right.$ median $\left.32^{\circ}\right)$. The mean LL at L1-S1 was $47.9^{\circ} \pm 12.8^{\circ}$ (median $\left.45^{\circ}\right)$. LLL at L4-S1 was $32.8^{\circ} \pm 7.6^{\circ}\left(\right.$ median $\left.33^{\circ}\right)$ and L5-S1 LL was $19.8^{\circ} \pm$ $12.3^{\circ}\left(\right.$ median $\left.18^{\circ}\right)$.

\section{Preoperative Clinical Data}

All included patients reported low-back pain. Leg pain was recorded in 42 patients (58.3\%). No motor weakness $(0 \%)$ was observed, while sensitive dysfunction was recorded in 12 patients $(16.7 \%)$. The median preoperative ODI score was $70.2 \% \pm 1.6 \%$ (range $55 \%-97 \%$ ), the median preoperative VAS score was $7.5 \pm 1.3$ (range 5-10). In group 1, the mean preoperative ODI score was $65 \% \pm$ $15 \%$, and the median ODI was 65 . The mean preoperative VAS score was $8.02 \pm 1.2$ (median 8 ). In group 2, the mean preoperative ODI score was $77.8 \% \pm 8.7$ (median 75.3), and the mean preoperative VAS score was $6.9 \pm 1.2$ (median 7).

\section{Intraoperative and Perioperative Data Group 1}

In group 1, a video-assisted mini-open anterior retroperitoneal approach with the patient supine was per- 

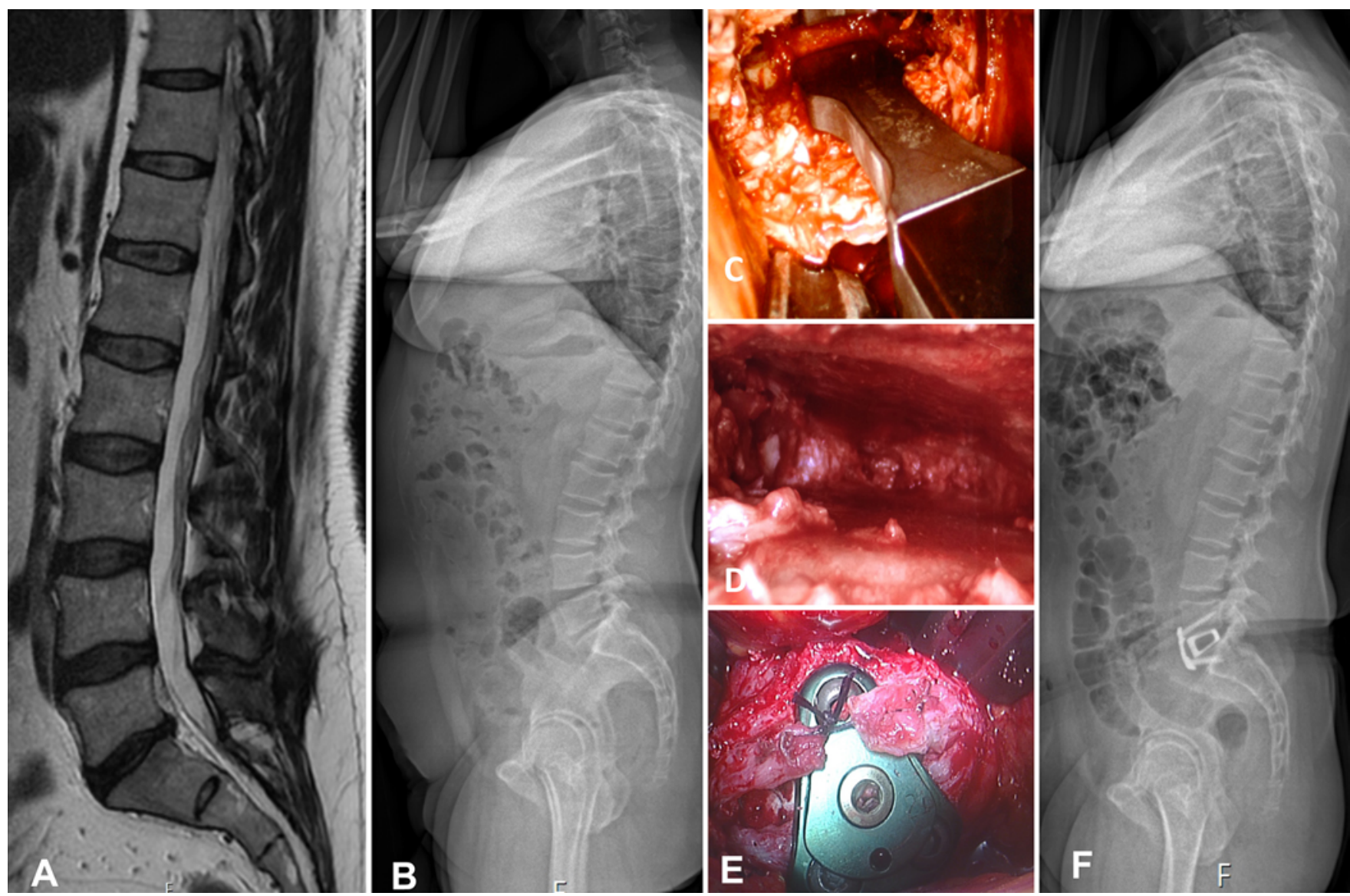

FIG. 2. Case example of 52-year-old man who suffered from low-back pain and left-side sciatica with sensory impairment at $L 5$ on the left, was resistant to conservative treatment, and underwent ALIF. A: Sagittal T2-weighted MR image showing L5-S1 Pfirrmann grade IV degeneration (inhomogeneous disc with a hypointense dark gray signal intensity and decreased disc height). B: Preoperative whole standing-spine radiograph showing normal sagittal and coronal balance. C-E: Intraoperative endoscopic view and magnification showing mobilization of the two vertebral bodies with a spreader, the posterior wall of the disc space, and the two preserved anterior ligament flaps sutured together once a 3-screw fixed plate stabilized the cage. F: Postoperative whole standing-spine radiograph showing L5-S1, the correct positioning of the cage, and L5-S1 lordosis.

formed in all cases with a standard transverse modified Pfannenstiel incision of $5 \mathrm{~cm} .^{12,14}$ The anterior sheath of the left rectus abdominis muscle was dissected longitudinally from the left side, approximately $2 \mathrm{~mm}$ lateral to the linea alba and the muscle retracted upward and laterally with careful blunt finger dissection. A short incision in the far lateral tract of the arcuate line allowed visualization of the retroperitoneal space. Under direct visual and endoscopic assistance $\left(30^{\circ}, 10-\mathrm{mm}\right.$ cold light endoscope coupled to a high-definition screen) the preparation of the anterior surface of the intervertebral disc was performed, paying special attention to the inferior hypogastric plexus between the iliac vessels after coagulation of the middle sacral vein and artery. Therefore, an autostable retractor with blades was put in place. After complete resection of the ALL, the vertebral bodies were then mobilized with a spreader, providing posterior indirect decompression in each case (Fig. 2). Thirty-four (94.4\%) $20^{\circ}$ lordotic-shaped titanium cages and $2(5.5 \%) 13^{\circ}$ lordotic-shaped tantalum cages filled with bone graft or bone substitute (tricalcium phosphate) were implanted (Fig. 3). A plate fixed with 3 screws secured each cage. The mean duration of surgery was $107.4 \pm 29.2$ minutes (median 102.5 minutes, range 90-120 minutes). The mean intraoperative blood loss was $188.9 \pm 52.2 \mathrm{ml}$ (median $200 \mathrm{ml}$, range 150-200 ml). Intraoperative surgical complications were recorded in 2 patients $(5.5 \%)$ : 1 case $(2.8 \%)$ of a small peritoneal tear repaired directly, and 1 case $(2.8 \%)$ of common iliac vein bleeding treated by surgical compression and hemostatic agents. The mean hospitalization duration was $6.4 \pm 1.1$ days (median 6 days, range 6-7 days). A total of 2 blood transfusions $(5.5 \%)$ were performed on 36 patients. Early postoperative complications were recorded in 2 cases: 1 superficial hematoma treated conservatively, and 1 postoperative new-onset radiculopathy subsequently treated with a posterior decompression (Table 1).

\section{Group 2}

In group 2, surgery was performed in all cases with a standard open posterior midline approach. Bilateral subperiosteal paraspinal muscle dissection, monolateral laminectomy, and medial bilateral artrectomy were per- 

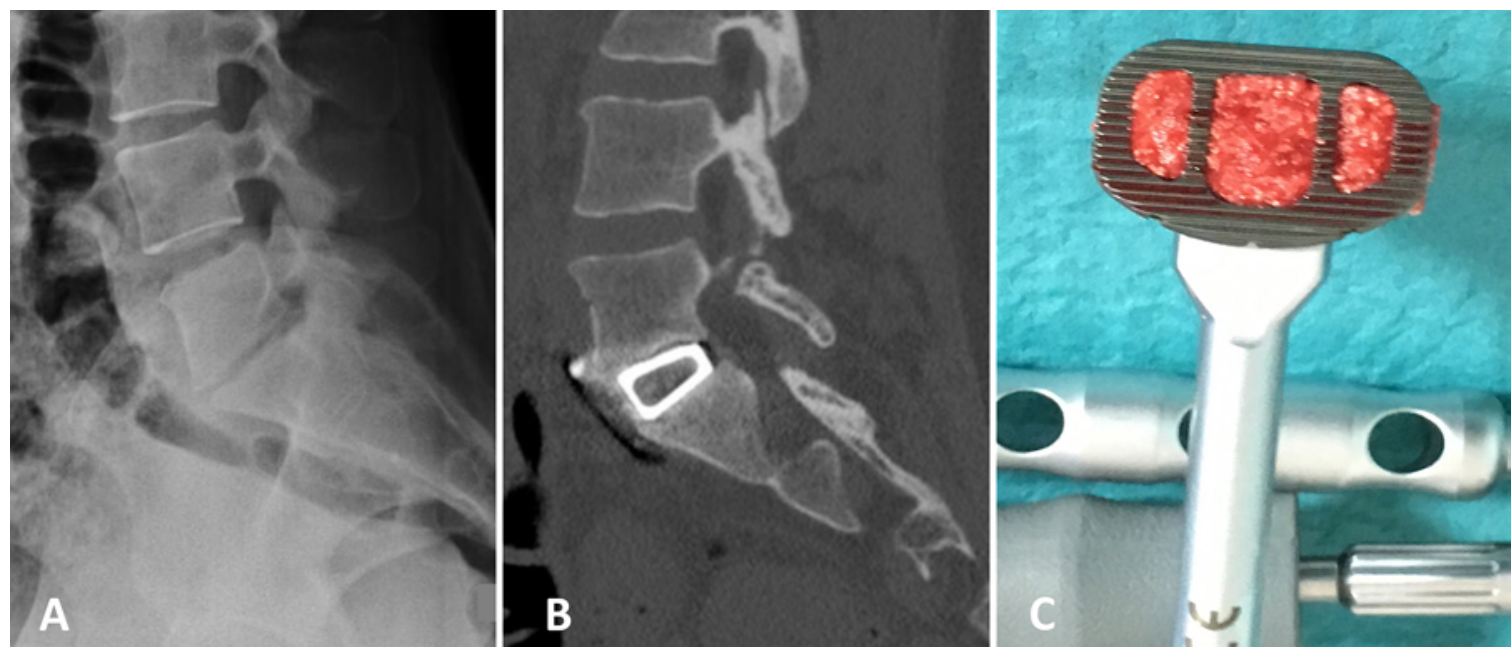

FIG. 3. Radiological evidence of collapsed disc height and segmental lordosis restoration after an anterior cage implant. A: Preoperative lumbar radiograph showing L5-S1 severe discopathy. B: Postoperative sagittal CT scan showing the lordotic-shaped cage. C: Intraoperative view of the cage filled by heterologous bone substitute.

formed in all cases. Transpedicular screw positioning was performed freehand with final fluoroscopic control. Once ipsilateral neural elements were decompressed if needed, discectomy was performed and parallel "banana"-shaped titanium cages (filled with bone autograft) or tantalum cages were implanted in the most anterior part of the interbody space to create a pivot for posterior compression, in order to restore segmental lordosis. Posterior autologous bone grafting was placed in all cases. The mean duration of surgery was $181.1 \pm 21.9$ minutes (median 180 minutes, range 135-210 minutes). Mean intraoperative blood loss was $387.1 \pm 145.5 \mathrm{ml}$ (median $350 \mathrm{ml}$, range $300-450 \mathrm{ml})$. One intraoperative surgical complication

TABLE 1. Intra- and perioperative data

\begin{tabular}{lccc}
\hline \multicolumn{1}{c}{ Variable } & ALIF $(n=36)$ & TLIF $(n=36)$ & $p$ Value \\
\hline Males/females & $12 / 24$ & $20 / 16$ & NA \\
\hline Mean age (SD), yrs & $46.09(9.15)$ & $50.55(13.41)$ & NA \\
\hline Diagnosis & & & NA \\
\hline DDD & $51(86 \%)$ & $28(78 \%)$ & \\
\hline PDS & $5(14 \%)$ & $8(22 \%)$ & \\
\hline Mean surgical time (SD), & $107.4(29.2)$ & $181.1(21.9)$ & $<0.0001$ \\
mins & & & \\
\hline Intraop blood loss, ml & & & $<0.0001$ \\
\hline \multicolumn{1}{c}{ Median (IQR) } & $200(150-200)$ & $350(300-450)$ & \\
\hline$\quad$ Mean (SD) & $188.9(52.2)$ & $387.1(145.5)$ & \\
\hline Intraop complications & $5.55 \%, n=2$ & $2.7 \%, n=1$ & 0.561 \\
\hline $\begin{array}{l}\text { Hospitalization length of } \\
\text { stay, days }\end{array}$ & & & 0.1303 \\
\hline \multicolumn{1}{l}{ Median (IQR) } & $6(6-7)$ & $7(6-7)$ & \\
\hline \multicolumn{1}{l}{ Mean (SD) } & $6.4(1.1)$ & $6.7(0.9)$ & \\
\hline Blood transfusion & $5.55 \%, n=2$ & $11.1 \%, n=4$ & 0.4095 \\
\hline Early postop complications & $5.55 \%, n=2$ & $2.7 \%, n=1$ & 0.561 \\
\hline
\end{tabular}

NA = not available. (a dural tear repaired directly) was recorded (2.8\%). The mean hospitalization length of stay was $6.7 \pm 0.9$ days (median 7 days, range 6-7 days). Blood transfusions were necessary in 4 patients (11.1\%). An early postoperative complication was recorded in 1 patient with residual postoperative sciatica $(2.8 \%)$, which was managed conservatively (Fig. 1D and E). Intra- and perioperative data are summarized in Table 1.

\section{Postoperative Spinopelvic Parameters}

In group 1 , the mean postoperative PI was $50^{\circ} \pm 9^{\circ}$ (median $46.5^{\circ}$ ), the mean PT was $17.2^{\circ} \pm 15.7^{\circ}$ (median $16.5^{\circ}$ ), and the mean SS was $32.9^{\circ} \pm 7.7^{\circ}$ (median $32^{\circ}$; Table 2). The mean LL at L1-S1 was $46.5^{\circ} \pm 11^{\circ}$ (median $45.5^{\circ}$ ), LLL at L4-S1 was $35.2^{\circ} \pm 6^{\circ}\left(\right.$ median $\left.35^{\circ}\right)$, and mean L5-S1 LL was $26.3^{\circ} \pm 5.6^{\circ}\left(\right.$ median $\left.25^{\circ}\right)$.

In group 2 , the mean postoperative PI was $50.6^{\circ} \pm 7.5^{\circ}$ (median $50^{\circ}$ ), the mean PT value was $18.6^{\circ} \pm 6.7^{\circ}$ (median $19.5^{\circ}$ ), and the mean SS was $31.5^{\circ} \pm 5.5^{\circ}\left(\right.$ median $\left.33^{\circ}\right)$. The mean LL at L1-S1 was $47.8^{\circ} \pm 9.8^{\circ}$ (median $45.5^{\circ}$ ), the LLL at L4-S1 was $34^{\circ} \pm 17.2^{\circ}$ (median $32.5^{\circ}$ ), and the mean LL at L5-S1 was $22.9^{\circ} \pm 5.7^{\circ}$ (median $23.5^{\circ}$; Table 2).

TABLE 2. Radiological data

\begin{tabular}{|c|c|c|c|c|c|}
\hline \multirow{2}{*}{$\begin{array}{c}\text { Radiological } \\
\text { Outcome }\end{array}$} & \multicolumn{2}{|c|}{ Group 1 Mean (SD) } & \multicolumn{2}{|c|}{ Group 2 Mean (SD) } & \multirow{2}{*}{$\begin{array}{c}\mathrm{p} \\
\text { Value }\end{array}$} \\
\hline & Preop & Postop & Preop & Postop & \\
\hline $\mathrm{PI}\left({ }^{\circ}\right)$ & $49.4(11)$ & $50(9)$ & $50.9(9.7)$ & $50.6(7.5)$ & NA \\
\hline $\mathrm{PT}\left({ }^{\circ}\right)$ & $16.8(7.3)$ & $17.2(15.7)$ & $17.2(10)$ & $18.6(6.7)$ & NA \\
\hline $\operatorname{SS}\left({ }^{\circ}\right)$ & $31.1(8.3)$ & $32.9(7.7)$ & $33.5(6)$ & $31.5(5.5)$ & NA \\
\hline L1-S1 LL $\left(^{\circ}\right)$ & $48.7(7.3)$ & $46.5(11)$ & $47.9(12.8)$ & $47.8(9.8)$ & NA \\
\hline $\begin{array}{l}\text { L4-S1 LLL } \\
\left({ }^{\circ}\right)\end{array}$ & $31.5(7.5)$ & $35.2(6)$ & $32.8(7.6)$ & $34(17.2)$ & NA \\
\hline L5-S1 LL $\left(^{\circ}\right)$ & $17(6.2)$ & $26.3(5.6)$ & $19.8(12.3)$ & $22.9(5.7)$ & $<0.001$ \\
\hline
\end{tabular}


TABLE 3. Functional data

\begin{tabular}{rccccc}
\hline $\begin{array}{c}\text { Functional } \\
\text { Outcome }\end{array}$ & $\begin{array}{c}\text { Mean } \\
\text { Preop }\end{array}$ & $\begin{array}{c}\text { Mean } \\
\text { Postop } \\
(\text { SD) }\end{array}$ & $\begin{array}{c}\text { Mean Last } \\
\text { Follow-Up } \\
(\text { SD })\end{array}$ & $\begin{array}{c}\text { Unchanged } \\
(\%)\end{array}$ & $\begin{array}{c}\text { Improved } \\
(\%)\end{array}$ \\
\hline ODI score & & & & & \\
\hline Group 1 & $65(15)$ & $25(12)$ & $15(7.1)$ & $1(2.8)$ & $35(97.2)$ \\
\hline Group 2 & $77.8(8.7)$ & $35(9.3)$ & $21(9.9)$ & $3(8)$ & $33(92)$ \\
\hline VAS score & & & & & \\
\hline Group 1 & $8.02(1.2)$ & $3.3(2)$ & $1.8(1.2)$ & NA & NA \\
\hline Group 2 & $6.9(1.2)$ & $3.4(1.2)$ & $2.5(1.3)$ & NA & NA \\
\hline Total & NA & NA & NA & $4(5.5)$ & $68(94.5)^{*}$ \\
\hline
\end{tabular}

Neither of the groups experienced worsened outcomes. ${ }^{*} p<0.001$

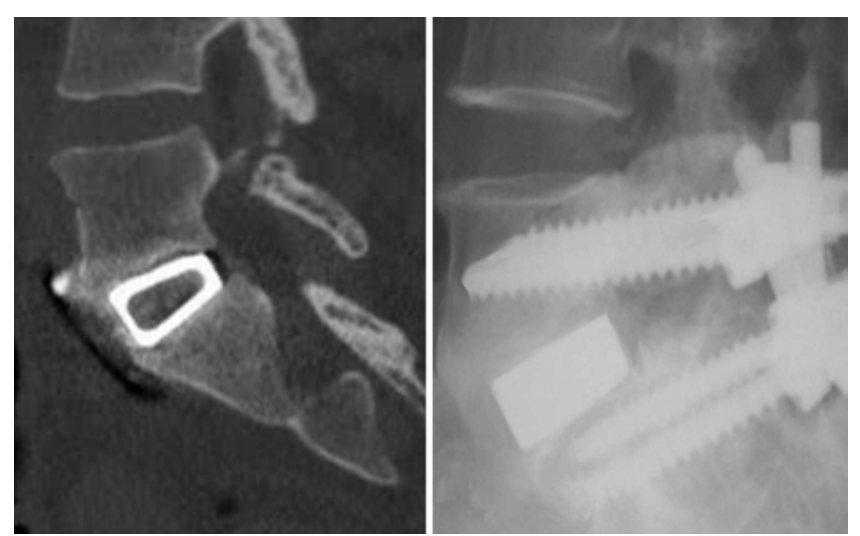

FIG. 4. Radiological evidence (left, CT image; right, radiograph) of interbody fusion in ALIF (left) and TLIF (right) at the last follow-up (Brantigan grade 5).

\section{Follow-Up Data}

In group 1, the mean postoperative ODI score at 12 months follow-up was $15 \% \pm 7.1 \%$ (median 13\%). The mean postoperative VAS score at 12 months follow-up was $1.8 \pm 1.2$ (median 1). The median time until return to work was 2.4 months. At last follow-up, functional improvement (ODI/VAS) was recorded in 35 patients $(97.2 \%)$ and in 1 patient remained stable. In group 2, the mean postoperative ODI score at 12 months follow-up was $21 \% \pm 9.9 \%$ (median 20\%). The mean postoperative VAS score at 12 months follow-up was $2.5 \pm 1.3$ (median 3 ). The median time until return to work was 3.2 months. At last followup, functional improvement (ODI/VAS) was recorded in 33 patients $(92 \%)$, and in 3 patients $(8 \%)$ remained stable (Table 3). Brantigan grade 4 or 5 was observed in all patients at the last follow-up. The presence of bone bridging in the anterior part of or into the cage was observed in all patients in both groups at final follow-up (Fig. 4). A delayed second surgery was necessary in 1 patient $(2.8 \%)$ in group 2 for adjacent disc disease (ADD). Preoperative sensory disturbance was persistent in 2 patients (1 in group 1 and 1 in group 2) at 24 months follow-up (5.5\%). Preoperative radicular pain improved in 40 patients $(96 \%)$ and remained unchanged in 2 patients (4\%) among the 42 patients with preoperative neurological symptoms.

\section{Surgical Considerations}

A shorter surgical time was recorded in group 1 (107.4 minutes) compared to group 2 (181.1 minutes) with a statistically significant difference $(\mathrm{p}<0.0001)$ between groups, as well as significantly reduced blood loss in group 1 ( 188.9 vs $387.1 \mathrm{ml}, \mathrm{p}<0.0001)$. No other variables between the two groups were significant, including hospitalization length of stay $(p=0.1303)$, number of postoperative blood transfusions $(p=0.4095)$, and perioperative complications $(\mathrm{p}=0.561 ;$ Table 1$)$.

\section{Radiological Evaluation}

Postoperative spinopelvic parameters were compared between the two groups. An ANOVA was performed on pre- and postoperative spinopelvic parameters. L5-S1 segmental increase of LL emerged between pre- and post-

operative values in groups $1(\mathrm{p}<0.001)$ and $2(\mathrm{p}<0.05)$, and was particularly greater in group 1 . The mean value of increase was $9^{\circ}$ (range $4.5^{\circ}-13.7^{\circ}$ ) in group 1 and $5^{\circ}$ (range $\left.0^{\circ}-10.5^{\circ}\right)$ in group $2(\mathrm{p}=0.023$; Table 2$)$.

\section{Clinical Evaluation}

The difference in the ODI values between preoperatively, 3 months, and 12 months follow-up was significant in both groups $(\mathrm{p}<0.001)$. In group 2 we observed a further significant improvement between 3 and 12 months ( $p$ $<0.05$ ), while in group 1 we found an early improvement of all the scores at 3 months follow-up. No significant differences emerged between the two groups at last follow-up because of persistent improvement in both groups (Table 3 ).

\section{Discussion}

Single-level L5-S1 interbody fusion is achieved through posterior or anterior techniques. The main advantages of posterior approaches are direct neural element decompression and posterolateral grafting for fusion. The drawbacks to this approach may be injury of neural structures and denervation of paraspinal muscles weakening the posterior tension band. ${ }^{17,8}$ The anterior approach can achieve an optimal restoration of segmental lordosis, especially in collapsed discs. ${ }^{1-6}$ It is possible an indirect decompression leads to faster recovery despite possible injuries to surrounding structures or vascular complications, without a significant difference in terms of fusion rate $(88.6 \%$ vs $91.9 \%, p=0.23$ ) compared to TLIF. ${ }^{1-6,15}$ We found a significant increase in segmental lordosis with ALIF compared with TLIF procedures.,10,12,13 Over the last decade, the development of mini-open approaches has increased the efficiency and safety of anterior surgery. ${ }^{9,14,16,17}$

\section{Intraoperative and Perioperative Data}

The analysis of our data showed a significant reduction of surgical duration and intraoperative blood loss in ALIF ( $p<0.0001$ ) when compared to TLIF. According to the literature, hospitalization length of stay is similar in the two groups ( 6 days for ALIF and 7 days for TLIF) ${ }^{18}$ 
Minor intraoperative surgical complications (1 small peritoneal tear and 1 minor bleeding from the common iliac vein) were recorded in 2 patients (5.5\%) for group 1 and directly repaired without any consequences. One intraoperative complication (2.8\%) was recorded in group 2 . Early postoperative complications were recorded in 3 patients (4.1\%): 2 patients in group 1 (5.5\%), and 1 patient in group $2(2.8 \%)$. We observed 1 postoperative superficial hematoma $(2.8 \%)$ in the ALIF group that did not required revision and 1 case of early sciatica for each group. Despite the fact that we did not find a significant difference between the two groups, our results are comparable to findings reported in the literature (4.4\% for the anterior approach and $5.9 \%$ for the posterior approach). ${ }^{15}$ In our series, 2 patients needed a second unexpected surgery: 1 patient in group 1 for acute postoperative radiculopathy due to a small disc fragment compressing the nerve root, and 1 patient in group 2 for delayed ADD at 1-year follow-up. Recent studies comparing approach-related complications between anterior and posterior procedures found different and conflicting results in terms of morbidity rate. Some authors have described a worse outcome in the posterior group and others concluded that anterior approaches might be associated with higher postoperative morbidity and reoperation rates than posterior approaches. ${ }^{17-19}$ Although we found a significant increase of blood loss in the TLIF group, we did not find a significant difference in complication and reoperation rates between the two approaches $(p=0.561)$. In our series, to reduce bias, we included only patients with 1 level of DDD treated by a single senior surgeon trained in anterior approaches, to limit the impact of the access-related complications in both groups. All ALIF procedures were performed by video-assisted mini-open exposure which, as reported in large series, is associated with lower intra- and perioperative complications ${ }^{20-24}$ (Table 1).

\section{Radiological Outcomes}

Significant differences regarding improvement in L5S1 segmental lordosis $(p<0.0001)$ favoring the ALIF group were observed. The ALIF procedure allows powerful space distraction by ALL resection and the insertion of large lordotic cages (Fig. 5). We recorded a greater median value of final L5-S1 lordosis $\left(25^{\circ}\right)$ probably because the cage acted as a pivot. In large series reported in the literature, radiographic outcome showed a significant greater disc height, segmental lordosis, and an increase of whole LL in ALIF versus TLIF groups. ${ }^{25-29}$ Compared to the TLIF technique, the ALIF procedure is associated with a better postoperative segmental lordosis restoration and may be a reasonable option in the presence of severe DDD, when an optimal sagittal alignment should be obtained and when direct spinal canal decompression is not need$\mathrm{ed}^{28,30}$ (Table 2). Even if it was not the main goal of this study, at the last 2-year follow-up evaluation we observed radiological evidence of fusion on radiography or CT (Fig. 4) in all patients. This result in both groups, confirmed by a senior radiologist, was surprising but not unique in the literature. ${ }^{25,26} \mathrm{~A}$ possible explanation could be that the small number of patients reduced the likelihood of observing patients without fusion. ${ }^{12,18,21}$ Furthermore, nonunion could have been a possible cause of patient dropout, so that

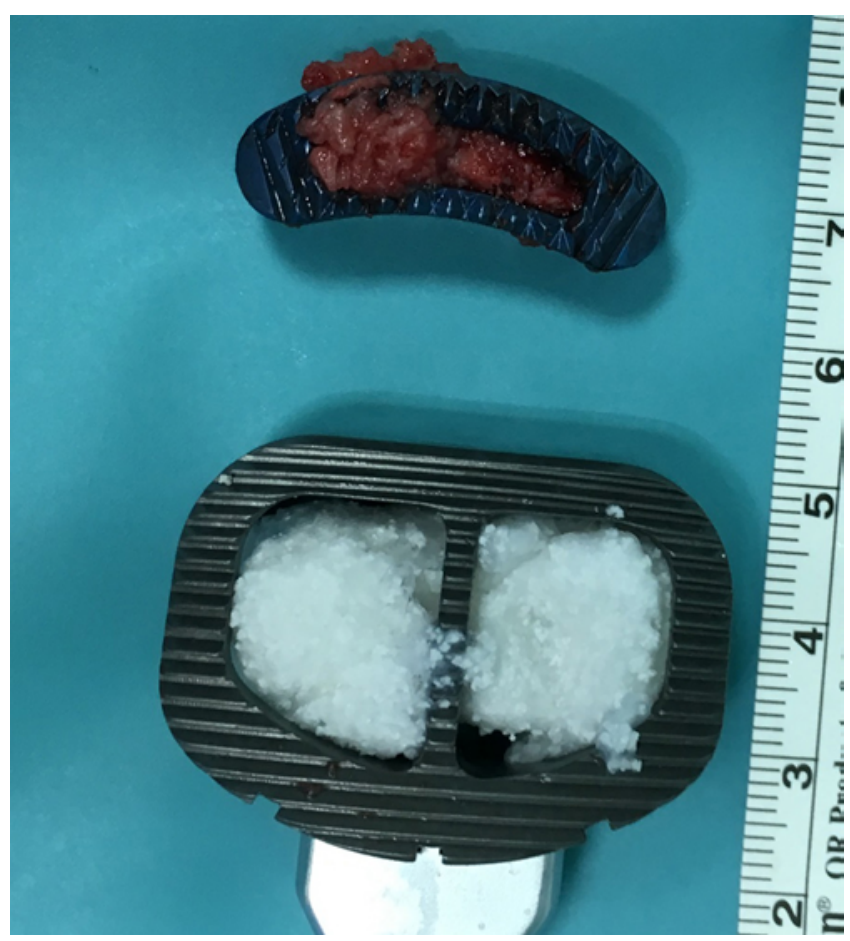

FIG. 5. In the upper part of the figure, a banana-shaped titanium cage filled by autologous bone commonly used in TLIF approaches is shown. In the lower half, a lordotic-shaped titanium cage filled by bone substitute used in ALIF is represented.

patients, because of persistent pain or other complaints, could have been referred to other centers.

\section{Clinical Outcome}

The mean 3-month postoperative ODI score was $25 \% \pm$ $12 \%$ (median 24\%) in group 1 and $35.5 \% \pm 9.3 \%$ (median $36 \%$ ) in group 2. ODI/VAS improvement was observed in 98\% of patients in group 1 and in $92 \%$ of group 2 at last follow-up. Although the ALIF group experienced a faster improvement and in the TLIF group the functional improvement between 3 and 12 months was significant ( $\mathrm{p}<$ 0.05 ), no significant differences emerged between the two groups at last follow-up. This result appears to emphasize the role of interbody fusion in the treatment of discogenic pain. ${ }^{1,18,20}$ Moreover, we found an early median time of return to work in the ALIF group (2.4 vs 3.2 months) compared to the TLIF group. These data could be explained because of the advantages of the anterior approach (more anatomical) but there is not strong evidence supporting this assumption ${ }^{20-22,25}$ (Table 3).

\section{Limitations}

The limitations of this study are the retrospective design and the small sample size, even if homogenous. Although we selected the pool of patients according to our standard criteria for choosing the approach, it could represent a possible selection bias that could be improved by further randomized studies. The involvement of a single institution and, moreover, a single surgeon may be a weak- 
ness (without comparison), but also a strength because of a reduction in technical variations or surgical bias. The rate of fusion we have observed at the final follow-up, confirmed by an independent senior radiologist, is anecdotal, although this was not the main goal of the study. Given the limited sample sizes, the data regarding fusion rate cannot be generalized.

\section{Conclusions}

Although a clinical benefit was achieved earlier in the ALIF group (faster return to work) compared with the TLIF group in this study, both procedures improved functional outcomes at last follow-up without a significant difference between the groups. ALIF procedures showed significantly $(p<0.0001)$ lower blood loss and shorter surgical duration when compared to TLIF. ALIF allows a powerful intervertebral disc distraction with significantly better segmental lordosis restoration, especially in collapsed discs, in comparison to TLIF ( $\mathrm{p}<0.001)$. Further prospective studies are necessary to evaluate complications and fusion rates in larger series, as well as possible influencing factors of ADD development between anterior and posterior approaches.

\section{References}

1. Schroeder GD, Kepler CK, Millhouse PW, et al. L5/S1 fusion rates in degenerative spine surgery: a systematic review comparing ALIF, TLIF, and axial interbody arthrodesis. Clin Spine Surg. 2016;29(4):150-155.

2. Giang G, Mobbs R, Phan S, et al. Evaluating outcomes of stand-alone anterior lumbar interbody fusion: a systematic review. World Neurosurg. 2017;104(104):259-271.

3. Phan K, Xu J, Scherman DB, et al. Anterior lumbar interbody fusion with and without an "access surgeon": a systematic review and meta-analysis. Spine (Phila Pa 1976). 2017;42(10): E592-E601.

4. Brau SA, Delamarter RB, Schiffman ML, et al. Vascular injury during anterior lumbar surgery. Spine J. 2004;4(4): 409-412.

5. Chiriano J, Abou-Zamzam AM Jr, Urayeneza O, et al. The role of the vascular surgeon in anterior retroperitoneal spine exposure: preservation of open surgical training. $J$ Vasc Surg. 2009;50(1):148-151.

6. Mobbs RJ, Phan K, Daly D, et al. Approach-related complications of anterior lumbar interbody fusion: results of a combined spine and vascular surgical team. Global Spine J. 2016; 6(2):147-154.

7. Hammad A, Wirries A, Ardeshiri A, et al. Open versus minimally invasive TLIF: literature review and meta-analysis. $J$ Orthop Surg Res. 2019;14(1):229.

8. Tormenti MJ, Maserati MB, Bonfield CM, et al. Perioperative surgical complications of transforaminal lumbar interbody fusion: a single-center experience. J Neurosurg Spine. 2012; 16(1):44-50.

9. Bassani R, Gregori F, Peretti G. Evolution of the anterior approach in lumbar spine fusion. World Neurosurg. 2019; 131(131):391-398.

10. Qureshi R, Puvanesarajah V, Jain A, et al. A comparison of anterior and posterior lumbar interbody fusions: complications, readmissions, discharge dispositions, and costs. Spine (Phila Pa 1976). 2017;42(24):1865-1870.

11. Brantigan JW, Steffee AD. A carbon fiber implant to aid interbody lumbar fusion. Two-year clinical results in the first 26 patients. Spine (Phila Pa 1976). 1993;18(14):2106-2107.
12. Audat Z, Moutasem O, Yousef K, Mohammad B. Comparison of clinical and radiological results of posterolateral fusion, posterior lumbar interbody fusion and transforaminal lumbar interbody fusion techniques in the treatment of degenerative lumbar spine. Singapore Med J. 2012;53(3): 183-187.

13. Tropiano P, Berjano P, Lamartina C, Schnake KJ. Anterior lumbar surgical approaches and techniques. Eur Spine J. 2016;25(4)(suppl 4):488-489.

14. Bassani R, Querenghi AM, Cecchinato R, et al. A new "keyhole" approach for multilevel anterior lumbar interbody fusion: the perinavel approach-technical note and literature review. Eur Spine J. 2018;27(8):1956-1963.

15. Than KD, Wang AC, Rahman SU, et al. Complication avoidance and management in anterior lumbar interbody fusion. Neurosurg Focus. 2011;31(4):E6.

16. Bassani R, Cecchinato R, Morselli C, et al. Video-assisted anterior retroperitoneal approach to the lumbar spine. a minimal invasive technique improved by the use of endoscopic camera to treat lumbar spine diseases. Int J Clin Med. 2016;7: 94-100.

17. Katz AD, Mancini N, Karukonda T, et al. Approach-based comparative and predictor analysis of 30-day readmission, reoperation, and morbidity in patients undergoing lumbar interbody fusion using the ACS-NSQIP Dataset. Spine (Phila Pa 1976). 2019;44(6):432-441.

18. Huang KT, Hazzard M, Thomas S, et al. Differences in the outcomes of anterior versus posterior interbody fusion surgery of the lumbar spine: a propensity score-controlled cohort analysis of 10,941 patients. J Clin Neurosci. 2015;22(5): 848-853.

19. Campbell PG, Yadla S, Malone J, et al. Complications related to instrumentation in spine surgery: a prospective analysis. Neurosurg Focus. 2011;31(4):E10.

20. Mobbs RJ, Loganathan A, Yeung V, Rao PJ. Indications for anterior lumbar interbody fusion. Orthop Surg. 2013;5(3): 153-163.

21. Jiang SD, Chen JW, Jiang LS. Which procedure is better for lumbar interbody fusion: anterior lumbar interbody fusion or transforaminal lumbar interbody fusion? Arch Orthop Trauma Surg. 2012;132(9):1259-1266.

22. Ye YP, Hu JW, Zhang YG, Xu H. Impact of lumbar interbody fusion surgery on postoperative outcomes in patients with recurrent lumbar disc herniation: analysis of the US national inpatient sample. J Clin Neurosci. 2019;70:20-26.

23. Ahlquist S, Park HY, Gatto J, et al. Does approach matter? A comparative radiographic analysis of spinopelvic parameters in single-level lumbar fusion. Spine J. 2018;18(11):1999_ 2008.

24. Bateman DK, Millhouse PW, Shahi N, et al. Anterior lumbar spine surgery: a systematic review and meta-analysis of associated complications. Spine J. 2015;15(5):1118-1132.

25. Westerlund LE, Borden M. Clinical experience with the use of a spherical bioactive glass putty for cervical and lumbar interbody fusion. J Spine Surg. 2020;6(1):49-61.

26. Jenkins NW, Parrish JM, Khechen B, et al. Outcomes of expandable interbody devices in lumbar fusion: a systematic review and meta-analysis. Clin Spine Surg. 2020;33(6): 230-243.

27. Phan K, Thayaparan GK, Mobbs RJ. Anterior lumbar interbody fusion versus transforaminal lumbar interbody fusionsystematic review and meta-analysis. Br J Neurosurg. 2015; 29(5):705-711.

28. Watkins RG IV, Hanna R, Chang D, Watkins RG III. Sagittal alignment after lumbar interbody fusion: comparing anterior, lateral, and transforaminal approaches. J Spinal Disord Tech. 2014;27(5):253-256.

29. Kim JS, Lee KY, Lee SH, Lee HY. Which lumbar interbody fusion technique is better in terms of level for the treatment 
of unstable isthmic spondylolisthesis? J Neurosurg Spine. 2010;12(2):171-177.

30. Park D, Mummaneni PV, Mehra R, et al. Predictors of the need for laminectomy after indirect decompression via initial anterior or lateral lumbar interbody fusion. J Neurosurg Spine. 2020;32(6):781-787.

\section{Disclosures}

The authors report no conflict of interest concerning the materials or methods used in this study or the findings specified in this paper.

\section{Author Contributions}

Conception and design: Bassani, Querenghi, Peretti. Acquisition of data: Morselli, Bassani, Querenghi, Nuara. Analysis and inter- pretation of data: Morselli, Bassani, Querenghi, Nuara, Peretti. Drafting the article: Morselli, Bassani. Critically revising the article: Bassani, Sconfienza, Peretti. Reviewed submitted version of manuscript: Morselli, Bassani, Sconfienza, Peretti. Statistical analysis: Morselli, Nuara. Radiological analysis: Sconfienza.

\section{Correspondence}

Carlotta Morselli: IRCCS Istituto Ortopedico Galeazzi, Milan, Italy.cmorselli822@gmail.com. 